\title{
A Study on the Outcome of Treatment among Patients with Hoarseness in a Tertiary Care Centre
}

\author{
Sharafudeen Sherin Sha ${ }^{1}$, Reghunathan Rajesh ${ }^{2}$ \\ ${ }^{1}$ Department of ENT, Government Medical College, Alappuzha, Kerala, India. \\ ${ }^{2}$ Department of ENT, Government Medical College, Thiruvananthapuram, Kerala, India.
}

\section{ABSTRACT}

\section{BACKGROUND}

Hoarseness is defined as the perceived rough, harsh or breathy quality of voice. Since both benign and malignant lesions can produce hoarseness, timely evaluation is very important because delay in the diagnosis of malignancy can adversely affect the outcome. We wanted to study the treatment and its outcome in patients with hoarseness of various aetiologies, and compare the response to treatment between various groups.

\section{METHODS}

This was a longitudinal study conducted in the Department of ENT in a tertiary care centre in south India. In patients with hoarseness, history was elicited, clinical examination was done, and perceptual evaluation of voice was made using GRBAS (Grade, Roughness, Breathiness, Asthenia, Strain) scale. Direct laryngoscopy and biopsy were done whenever suspicious lesions were seen. Early laryngeal cancer was treated with radiotherapy, while advanced cases were treated with chemoradiation. Other cases were treated with medications, Video Laryngeal Surgery (VLS) or voice therapy, according to the diagnosis. Patients were kept under follow up; reassessment was done after six months regarding improvement/ persistence/ deterioration of previous symptoms. Laryngoscopy and perceptual evaluation of voice were repeated, and the data collected was analysed.

\section{RESULTS}

On treatment, the lesion subsided completely, and hoarseness got relieved in all the cases of laryngitis, trauma, vocal nodule, vocal polyp and cyst, while the lesion subsided partially, and hoarseness improved in vocal cord palsy, papilloma and carcinoma of glottis. The response to treatment was better in benign lesions when compared to malignant lesions ( $\mathrm{P}$ value $<0.0001$ ) and better in glottic malignancies when compared to malignancies at other nearby sites ( $\mathrm{P}$ value $<0.001$ ).

\section{CONCLUSIONS}

Most of the benign conditions that caused hoarseness subsided and voice became normal with medications, video laryngeal surgery and voice therapy, while hoarseness persisted to some extent after treatment with radiotherapy or chemoradiation in most of the patients with malignancy.

\section{KEY WORDS}

Hoarseness, GRBAS Scale, Carcinoma of Larynx, Video Laryngeal surgery, Chemo Radiation, Voice Therapy
Corresponding Author: Dr. Reghunathan Rajesh, Sreekovil, TC-96/577,

Snehatheeram Lane, Thuruvikkal PO., Trivandrum-695031, Kerala, India.

E-mail: drrrajeshent@gmail.com

DOI: $10.14260 /$ jemds/2020/274

Financial or Other Competing Interests: None.

How to Cite This Article:

Sha SS, Rajesh R. A study on the outcome of treatment among patients with hoarseness in a tertiary care centre. J. Evolution Med. Dent. Sci. 2020;9(15):1261-1266, DOI: 10.14260/jemds/2020/274

Submission 24-01-2020,

Peer Review 21-03-2020,

Acceptance 28-03-2020,

Published 13-04-2020.

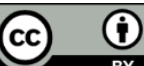




\section{BACKGROUND}

Hoarseness is the term used to describe a change in normal voice quality and it is invariably the earliest manifestation of a large variety of conditions directly or indirectly affecting the voice apparatus ${ }^{1}$. Although patients frequently complain of hoarseness, it is a nonspecific term for a symptom and not a diagnosis. Since both benign and malignant lesions can produce hoarseness, proper evaluation is very important because delay in the diagnosis of malignancy can adversely affect the outcome. In India and other developing countries, the prevailing low economic status, poor nutrition, poor general health of population, different food habits, vocal habits, smoking and drinking habits, unhealthy environment and different social customs definitely influence the incidence of hoarseness. The advent of fibreoptic telescope and stroboscope have reduced our dependence on mirror examination and greatly improved the diagnostic ability in cases of hoarseness. With the introduction of micro laryngoscopic surgery and video laryngeal surgery (VLS) using LASER, coblator, etc., great advancement has occurred in the treatment of laryngeal pathologies leading to hoarseness.

\section{Evaluation of a Patient with Hoarseness}

In evaluating hoarseness, a thorough elicitation of clinical history and examination of the head and neck including indirect laryngoscopy allow the clinician to assess the possible aetiologies, and to target the investigations and planning of appropriate management. Telescopic laryngeal examination, flexible fiberoptic laryngoscopy, operative direct laryngoscopy, stroboscopy, computerized voice analysis, videokymography, photoglottography, laryngeal electromyography, computed tomography, magnetic resonance imaging and high-speed digital imaging are some of the investigative procedures.

Hoarseness may be due to congenital conditions (e.g. vocal cord web), trauma (e.g. vocal cord haemorrhage, cricoarytenoid dislocation), inflammation (e.g. laryngitis, tuberculosis), non-neoplastic mass lesions (e.g. vocal cord polyp, vocal cord cyst, Reinke's oedema), benign neoplasms (e.g. papilloma), premalignant lesions (e.g. keratosis), malignancies (e.g. carcinoma), neurological conditions (e.g. vocal cord palsy), structural lesions due to muscle tension dysphonia (e.g. vocal nodules) or some miscellaneous conditions ( e.g. hypothyroidism, myasthenia gravis).

\section{Measurements of Degree of Hoarseness}

An additional component of assessing hoarseness is the perceptual component, from either the patient's perspective or the clinician's perspective. Both aim to quantify the severity of the voice impairment.

a. Self-Rated Assessments

Several commonly used perceptual rating systems are intended to better characterize dysphonia and to assess the negative impact of voice disturbance on a patient's quality of life. The more widely known among them are the 30 -question Voice Handicap Index $(\mathrm{VHI})^{2}$ with its revised, streamlined 10-question version (VHI-10) ${ }^{3}$ and the Voice-Related Quality of Life survey (V-RQOL). ${ }^{4}$

b. Clinician-Rated Measures

Two clinician-rated scales are commonly used to assess the acoustic quality and severity of voice disorders. The GRBAS (overall grade [G], roughness [R], breathiness [B], asthenia-weakness [A], and strain [S]) is a clinician-based 0 -point to 3-point graded assessment of quality and severity of voice disorder ${ }^{5}$. The Consensus AuditoryPerceptual Evaluation of Voice (CAPE-V) is another provider-rated system developed by the American Speech-Language-Hearing Association ${ }^{6}$. It is a standardized measure of roughness, breathiness, strain, pitch, and loudness. Although these tools allow for an objective quantification of the severity of voice disorders, no evidence has demonstrated that they influence the diagnosis or treatment of patients who present with dysphonia. Without data to suggest additional diagnostic or treatment benefit, these tools may be useful for research purposes and communication among clinicians, but use in clinical practice is at the discretion of the treating clinician.

\section{METHODS}

\section{Settings and Design}

This was a longitudinal study conducted in the Department of ENT in Govt. Medical College, Thiruvananthapuram which is a tertiary care centre in south India.

\section{Objectives}

To study the treatment and its outcome in patients with hoarseness of various aetiologies, and to compare the response to treatment between various groups.

\section{Selection Criteria}

Patients with hoarseness above the age of 12 were included. All voice disorders other than hoarseness were excluded.

\section{Sample Size}

The sample size was calculated to be a minimum of 150 (calculated using the formula $(\mathrm{Z} \alpha)^{2} \mathrm{pq} / \mathrm{d}^{2}$ where $\mathrm{Z} \alpha=1.96$, $\mathrm{p}$ was the proportion which was taken as $39 \%, q=100-p$ and $\mathrm{d}=20 \%$ of $\mathrm{p}$ )
Methodology
After getting clearance from the institutional ethical committee for research works and getting informed consent from the patients, history was elicited with reference to the onset, progression, duration, age, occupation, habits and associated symptoms. ENT examination including indirect laryngoscopy was done. Telescopic laryngeal examination or flexible laryngoscopy was done when there was difficulty in visualising larynx with a mirror. Perceptual evaluation of voice was made using GRBAS scale ${ }^{5}$. Direct laryngoscopy followed by biopsy or video laryngoscopic excision biopsy 
was done whenever suspicious lesions were seen, and further treatment was given according to histopathological results. Early laryngeal cancer was treated with radiotherapy, while advanced cases were treated with chemoradiation. Other cases were treated according to the diagnosis in each case. Patients were kept under follow up; reassessment was done after six months regarding improvement/persistence/ deterioration of previous symptoms. Laryngoscopy and perceptual evaluation of voice was repeated.

\section{Statistical Analysis}

The data collected was analyzed using SPSS software version 22; Chi-squared test and P-value were studied.

\section{RESULTS}

\section{I (A) Sex, Age, Duration and Habits}

A total of 106 males (70.6\%) and 44 females (29.3\%) presented with hoarseness with male: female ratio of 2.4: 1 . Maximum number of males were in the age group $51-60$ years and females in the age group of 31-40. Duration of hoarseness ranged from 2 days to more than 5 years. It was less than 1 month in 93(62\%) patients. The most common habit which might have predisposed to the disease was smoking in males (75.5\%) and vocal abuse in females (72.7\%).

\section{I (B) Occupation}

According to their occupation, patients were classified into four groups as follows

Level I (Elite Vocal Performers):

Included sophisticated voice users like the singers and actors, where even a slight vocal difficulty causes serious consequences to them and their career

Level II (Professional Voice Users):

For whom even moderate vocal difficulty would hamper adequate job performance. Clergymen, lecturers, politicians, public speakers, and telephone operators would be included in this level of voice users.

\section{Level III (Non-Vocal Professionals):}

It includes lawyers, salesmen/women etc. They can perform their jobs with slight or moderate voice problems; only severe dysphonia endangers adequate job performance.

Level IV (Non-Vocal Non-Professionals):

Includes labourers, homemakers and clerk. These are the persons who are not impeded from doing their work when they experience any kind of dysphonia. Majority of patients were non vocal non-professionals (85.3\%) which included manual labourers, housewives etc.

\section{I (C) Diagnosis}

Among the 106 males, the most frequent diagnosis was carcinoma glottis (29.2\%). Among the 44 females, the most frequent diagnosis was vocal cord nodule $(40.9 \%)$. The incidence of malignancy was $47 \%$ in males and $6.8 \%$ in females.

\begin{tabular}{|cccc|}
\hline Diagnosis & Female & Mex & Total \\
Acute laryngitis & 6 & 4 & 10 \\
Trauma & 0 & 5 & 5 \\
Carcinoma Supraglottis & 0 & 16 & 16 \\
Carcinoma Glottis & 1 & 31 & 32 \\
Carcinoma Subglottis & 1 & 1 & 2 \\
Carcinoma hypopharynx & 1 & 2 & 3 \\
Chronic nonspecific laryngitis & 9 & 5 & 14 \\
Vocal cord paralysis & 1 & 8 & 9 \\
Vocal cord nodule & 18 & 5 & 23 \\
Vocal cord papilloma & 1 & 1 & 2 \\
Vocal cord polyp & 4 & 21 & 25 \\
Vocal cord cyst & 2 & 1 & 3 \\
Actinomycosis & 0 & 1 & 1 \\
Vocal cord keratosis & 0 & 4 & 4 \\
Histoplasmosis & 0 & 1 & 1 \\
Total & $\mathbf{4 4}$ & $\mathbf{1 0 6}$ & $\mathbf{1 5 0}$ \\
\hline Table 1. Diagnosis $\boldsymbol{~ S e x ~}$ Distribution \\
\hline
\end{tabular}

\section{I (D) Treatment}

Most of the patients with benign pathologies were referred for voice therapy and were advised vocal conservation and maintenance of vocal hygiene. Acute laryngitis, trauma, chronic nonspecific laryngitis, actinomycosis and histoplasmosis were treated with medications. Vocal cord polyp, papilloma, cyst and keratosis were treated by video laryngeal surgery (VLS). Squamous cell carcinoma of the larynx and hypopharynx were treated by radiotherapy or chemo radiation depending on the stage after conforming diagnosis by direct laryngoscopy and biopsy. Vocal cord nodule and vocal cord palsy were treated by voice therapy. Patients with vocal cord palsy were advised complete chest, cardiovascular and neurological evaluation to detect underlying pathology. Overall $35.3 \%$ patients had undergone chemo/radiotherapy, $22.6 \%$ had undergone video laryngeal surgery, $21.3 \%$ had undergone voice therapy and $20.6 \%$ had undergone medical therapy.

\section{II (A) Follow up}

Follow up of all patients were done after 6 months. Patients were categorized into 4 groups based on indirect/ flexible laryngoscopy and perceptual evaluation of voice. Some of the patients with carcinoma larynx had to undergo tracheostomy due to airway obstruction by the tumour.

1. Lesion subsided completely and hoarseness relieved.

2. Lesion subsided partially and hoarseness improved.

3. Lesion remained the same and no change in hoarseness.

4. Lesion worsened and hoarseness increased.

5. Tracheostomised.

\begin{tabular}{|ccccccc|}
\hline Diagnosis & \multicolumn{7}{c|}{ Follow Up } & \multirow{2}{*}{ Total } \\
Histoplasmosis & I & II & III & IV & V & \\
Acute laryngitis & 0 & 1 & 0 & 0 & 0 & 1 \\
Trauma & 10 & 0 & 0 & 0 & 0 & 10 \\
Squamous cell carcinoma supraglottis & 5 & 0 & 0 & 0 & 0 & 5 \\
Squamous cell carcinoma glottis & 0 & 4 & 5 & 3 & 4 & 16 \\
Squamous cell carcinoma subglottis & 0 & 1 & 0 & 0 & 1 & 2 \\
Squamous cell carcinoma hypopharynx & 0 & 2 & 1 & 0 & 0 & 3 \\
Chronic nonspecific laryngitis & 14 & 0 & 0 & 0 & 0 & 14 \\
Vocal cord paralysis & 0 & 6 & 1 & 2 & 0 & 9 \\
Vocal cord nodule & 23 & 0 & 0 & 0 & 0 & 23 \\
Vocal cord papilloma & 0 & 2 & 0 & 0 & 0 & 2 \\
Vocal cord polyp & 25 & 0 & 0 & 0 & 0 & 25 \\
Vocal cord cyst & 3 & 0 & 0 & 0 & 0 & 3 \\
Actinomycosis & 0 & 1 & 0 & 0 & 0 & 1 \\
Vocal cord keratosis & 2 & 2 & 0 & 0 & 0 & 4 \\
Total & $\mathbf{8 2}$ & $\mathbf{4 6}$ & $\mathbf{9}$ & $\mathbf{7}$ & $\mathbf{6}$ & $\mathbf{1 5 0}$ \\
\hline Table 2. Diagnosis $\mathbf{\&}$ Follow $\boldsymbol{U p}$ & & & \\
\hline
\end{tabular}




\section{II (B) Occupation}

Hoarseness subsided/ improved in $82 \%$ of patients who were non-vocal non-professionals, while improvement was seen in all the patients in the other groups.

\begin{tabular}{|cccc|}
\hline Occupation & $\begin{array}{c}\text { Lesion and Hoarseness } \\
\text { Subsided/Improved No Improvement }\end{array}$ & Total \\
Elite vocal performers & 2 & 0 & 2 \\
Professional voice users & 6 & 0 & 6 \\
Non-vocal professionals & 14 & 0 & 14 \\
Non-vocal non-professionals & 105 & 23 & 128 \\
Total & $\mathbf{1 2 7}$ & $\mathbf{2 3}$ & $\mathbf{1 5 0}$ \\
\hline Table 3. Analysis of Occupation and Treatment Response \\
\hline
\end{tabular}

\section{II (C) Type of Lesion}

When comparing the outcome between malignant and nonmalignant lesions it was clear that results were better with non-malignant lesions. The outcome was analysed using Chi square test and there was significant statistical association between non-malignant lesions and treatment response when compared to malignant lesions. (P value $<0.0001$ )

\begin{tabular}{|c|c|c|c|c|c|}
\hline \multirow{2}{*}{$\begin{array}{l}\text { Type of } \\
\text { Lesion }\end{array}$} & \multicolumn{2}{|c|}{ Lesion and Hoarseness } & \multirow[b]{2}{*}{ Total } & \multirow{2}{*}{$\begin{array}{c}\text { Chi } \\
\text { Squared }\end{array}$} & \multirow{2}{*}{ P Value } \\
\hline & $\begin{array}{l}\text { Subsided/ } \\
\text { Improved }\end{array}$ & $\begin{array}{c}\text { No } \\
\text { Improvement }\end{array}$ & & & \\
\hline Malignant & 34 & 19 & 53 & \multirow{3}{*}{29.38} & \multirow{3}{*}{$<0.0001$} \\
\hline Benign & 94 & 3 & 97 & & \\
\hline Total & 128 & 22 & 150 & & \\
\hline \multicolumn{6}{|c|}{ Table 4. Analysis of Type of Lesion and Treatment Response } \\
\hline
\end{tabular}

\section{II (D) Site of malignancy}

There was significant statistical association between glottic malignancy and treatment response when compared to malignancy at other sites i.e., supraglottis, subglottis and hypopharynx. $(\mathrm{p}$ value $=0.00015)$

\begin{tabular}{|cccccc|}
\hline $\begin{array}{c}\text { Site of } \\
\text { Malignancy }\end{array}$ & $\begin{array}{c}\text { Lesion and Hoarseness } \\
\text { Improved }\end{array}$ & No Improvement & Total & $\begin{array}{c}\text { Chi } \\
\text { Squared }\end{array}$ & P Value \\
Glottis & 27 & 5 & 32 & & \\
Other sites & 7 & 14 & 21 & 14.36 & 0.00015 \\
Total & $\mathbf{3 4}$ & $\mathbf{1 9}$ & $\mathbf{5 3}$ & & \\
\hline Table 5. Analysis of Site of Malignancy and Treatment Response & \multicolumn{5}{|r}{} \\
\hline \multicolumn{6}{|r}{}
\end{tabular}

\section{II (E) Type of Treatment and Response}

Hoarseness subsided/ improved in all cases who had undergone video laryngeal surgery and medical treatment while hoarseness improved in $90.6 \%$ of those who had undergone voice therapy and $64.1 \%$ of those who had undergone radiotherapy or chemo radiation.

\begin{tabular}{|cccc|}
\hline \multirow{2}{*}{ Type of Treatment } & \multicolumn{2}{c|}{ Lesion and Hoarseness } & \multirow{2}{*}{ Total } \\
Medical Treatment & 31 & 0 & 31 \\
VLS & 34 & 0 & 34 \\
Voice therapy & 29 & 3 & 32 \\
Chemo/radiotherapy & 34 & 19 & 53 \\
Total & $\mathbf{1 2 8}$ & $\mathbf{2 2}$ & $\mathbf{1 5 0}$ \\
\hline Table 6. Analysis of Type of Treatment and Response \\
\hline \multicolumn{4}{|r}{} \\
\hline
\end{tabular}

\section{DISCUSSION}

A total of 150 cases of Hoarseness were studied during the study period.

\section{(A) Age, Sex, Duration, Habits and Occupation}

Majority of patients (26\%) were in the fifth decade. In a study by Hansa $\mathrm{B}$ et $\mathrm{al}^{1}$ also, majority of patients were in the fifth decade (22.31\%). Male: female ratio in our study was 2.4: 1 while Hansa $\mathrm{B}$ et $\mathrm{al}^{1}$ observed a ratio of 1.89:1. Many other studies also showed male predominance. $62 \%$ of patients presented within 1 month. In the study by Hansa B et al, ${ }^{1}$ most of the presenting complaints (61.35\%) were seen within 3 months; $25.10 \%$ within 3 to 6 months and $10.76 \%$ within 6 to 12 months; $20.72 \%$ complaints were of more than 1-year duration.

The most common habit was smoking (54\%). Hansa B et $\mathrm{al}^{1}$ also observed smoking (43\%) as the commonest habit followed by vocal abuse (31\%), alcohol intake $(29.48 \%)$ and tobacco/gutkha chewing (29.48\%). Baitha S et al7 observed smoking in $25.45 \%$ of cases, tobacco chewing in $17.27 \%$ and alcohol intake in $12.72 \%$. Majority of patients were non-vocal non-professionals (85.3\%). Hansa B et $\mathrm{al}^{1}$ also found $85.26 \%$ non-vocal non-professionals, $9.56 \%$ non-vocal professionals, $3.59 \%$ professional voice users and $1.59 \%$ elite vocal performers which is almost similar to our study.

\section{(B) Diagnosis}

The commonest diagnosis was squamous cell carcinoma glottis $(21.3 \%)$. The reason for hoarseness in case of carcinoma supraglottis, subglottis and hypopharynx is due to extension to glottis or due to vocal cord fixity. In the study by Hansa $\mathrm{B}$ et $\mathrm{al}^{1}$ nodule was most common lesion found $(11.95 \%)$ followed by vocal cord palsy (11.16\%),chronic laryngitis $(9.56 \%)$, malignancy $(9.56 \%)$, vocal cyst $(5.58 \%)$, oedema (5.18\%), acute laryngitis (4.38\%), bowing (3.98\%), vocal polyp (3.59\%), sulcus vocalis $(2.79 \%)$ and abductor palsy $(2.39 \%)$.

The overall incidence of malignancy was $35.3 \%$ with a male female ratio of $17: 1$. In the study by Bhaita $\mathrm{S}$ et $\mathrm{al}^{7}{ }^{7}$ the incidence of malignancy was $14.54 \%$ with male to female ratio as $15: 1$. Since the hospitals in periphery lacks the facility of managing malignancy larynx and hypopharynx, most of these cases will be referred to our hospital which is a tertiary care centre where as majority of the benign pathologies are treated in peripheral hospitals itself. This may be the reason for the high incidence of malignancy in our study.

The incidence of vocal nodule was $15.3 \%$ with a male female ratio of $1: 3.5$. Hansa B et al $^{1}$ observed $11.95 \%$ of vocal nodule with a male female ratio 1:1.7. The incidence of vocal cord polyp was $16.6 \%$ with a male female ratio of $5: 1$. In study by Ghosh SK et al, ${ }^{8}$ incidence of vocal cord polyp was $23 \%$ with male to female ratio of 3.6:1 The incidence of vocal cord paralysis was $6 \%$ with a male female ratio of $8: 1$. In study by Baitha $\mathrm{S}$ et $\mathrm{al}^{7}{ }^{7}$ incidence of vocal cord paralysis was $9 \%$ with male to female ratio of 9:1

\section{(C) Treatment}

Vocal cord nodule and vocal cord palsy were treated by voice therapy. A study by Fu S et $\mathrm{al}^{9}$ showed that individuals with vocal fold nodules are able to maintain improved voice quality and vocal health following intensive voice treatment. Studies by El-Banna $\mathrm{M}$ et al ${ }^{10}$ Kao $\mathrm{YC}$ et al ${ }^{11}$ and Busto-Crespo 0 et al $^{12}$ suggested the importance of early voice therapy in vocal cord palsy. Early glottic squamous cell carcinoma was 
treated by radiotherapy. In case of early glottic cancer, though studies by Czecior E et al, ${ }^{13}$ Cohen SM et al ${ }^{14}$ and Loughran $\mathrm{S}$ et $\mathrm{al}^{15}$ showed no significant difference in voice quality after treatment with radiotherapy and endoscopic laser excision, studies conducted by Aaltonen LM et al ${ }^{16}$ and Jotic A et $\mathrm{al}^{17}$ suggested that patients treated with radiotherapy showed better voice quality. Also, studies done by Hocevar-Boltezar I et al, ${ }^{18}$ Karlsson $\mathrm{T}$ et al ${ }^{19}$ and Tuomi $\mathrm{L}$ et $\mathrm{al}^{20}$ proved the importance of voice rehabilitation after radiotherapy in early glottis cancer.

Advanced carcinoma of the larynx and hypopharynx were treated by concurrent chemoradiation. A study by AlMamgani A et $\mathrm{al}^{21}$ showed that addition of chemotherapy to radiotherapy in T3 laryngeal cancer significantly improved laryngectomy-free survival. As per the studies by Carrara-de Angelis $\mathrm{E}$ et $\mathrm{al}^{22}$ and Fung $\mathrm{K}$ et $\mathrm{al}^{23}$, voice-related quality of life was better in patients after chemoradiation compared to laryngectomy in advanced laryngeal cancer.

\section{(D) Analysis of Treatment Response}

The response to treatment was better in benign lesions when compared to malignant lesions ( $\mathrm{P}$ value $<0.0001$ ), and better in glottic malignancies when compared to malignancies at other sites ( $\mathrm{P}$ value $<0.001$ ). A study by Gillespie AI et $\mathrm{al}^{24}$ showed that treatment was successful in improving acoustic voice parameters in most of the benign lesions. As per the study by Tuomi L et al ${ }^{25}$, voice was worse in glottic when compared to supraglottic malignancy initially, but after treatment, voice was better in glottic when compared to supraglottic malignancy. The results of these studies were comparable with those of the present study.

\section{CONCLUSIONS}

Smoking was the most common predisposing factor and carcinoma glottis was the most common diagnosis in males whereas vocal abuse was the most common predisposing factor and vocal nodule was the most common diagnosis in females. Majority of the patients were non-vocal nonprofessionals, but improvement in hoarseness was not seen in all those patients. Improvement in hoarseness was seen in all the patients in the other groups. Most of the benign conditions that caused hoarseness subsided and voice became normal with medications, video laryngeal surgery and voice therapy, while hoarseness persisted to some extent after treatment in most of the patients with malignancy after treatment with radiotherapy or chemoradiation. Improvement in voice was significantly better in nonmalignant lesions when compared to malignant lesions and in carcinoma glottis when compared to carcinoma of other nearby areas like supraglottis, subglottis and hypopharynx.

\section{REFERENCES}

[1] Hansa B, Varsha M, Digvijay S, et al. Hoarseness of voice: a retrospective study of 251 cases. International Journal of Phonosurgery and Laryngology 2011;1 (1):21-7.
[2] Maertens K, De Jong FICRS. The voice handicap index as a tool for assessment of the biopsychosocial impact of voice problems. B-ENT 2007;3 (2):61-6.

[3] Rosen CA, Lee AS, Osborne J, et al. Development and validation of the voice handicap index-10. Laryngoscope 2004;114 (9):1549-56.

[4] Morzaria S, Damrose EJ. A comparison of the VHI, VHI-10 and V-RQOL for measuring the effect of Botox therapy in adductor spasmodic dysphonia. J Voice 2010;26 (3):37880.

[5] Yamaguchi H, Shrivastav R, Andrews ML, et al. A comparison of voice quality ratings made by Japanese and American listeners using the GRBAS scale. Folia Phoniatr Logop 2003;55 (3):147-57.

[6] Zraick RI, Kempster GB, Conner NP, et al. Establishing validity of the Consensus Auditory-Perceptual Evaluation of Voice (CAPE-V). Am J Speech Lang Pathol 2011;20 (1):14-22.

[7] Baitha S, Raizada RM, Singh AKK, et al. Clinical profile of hoarseness of voice. Indian Journal of Otolaryngology and Head and Neck Surgery 2002;54 (1):14-8.

[8] Ghosh SK, Chattopadhyay S, Bora H, et al. Microlaryngoscopic study of 100 cases of hoarseness of voice. Indian Journal of Otolaryngology and Head and Neck Surgery 2001;53 (4):270-2.

[9] Fu S, Theodoros D, Ward EC. Long-term effects of an intensive voice treatment for vocal fold nodules. Int J Speech Lang Pathol 2016;18 (1):77-88.

[10] El-Banna M, Youssef G. Early voice therapy in patients with unilateral vocal fold paralysis. Folia Phoniatr Logop 2014;66 (6):237-43.

[11] Kao YC, Chen SH, Wang YT, et al. Efficacy of voice therapy for patients with early unilateral adductor vocal fold paralysis. J Voice 2017;31(5):567-75.

[12] Busto-Crespo O, Uzcanga-Lacabe M, Abad-Marco A, et al. Longitudinal voice outcomes after voice therapy in unilateral vocal fold paralysis. J Voice 2016;30 (6):767.e9-e15.

[13] Czecior E, Orecka B, Pawlas P, et al. Comparative assessment of the voice in patients treated for early glottis cancer by laser cordectomy or radiotherapy. Otolaryngol Pol 2012;66 (6):407-12.

[14] Cohen SM, Garrett CG, Dupont WD, et al. Voice-related quality of life in T1 glottic cancer: irradiation versus endoscopic excision. Ann Otol Rhinol Laryngol 2006;115 (8):581-6.

[15] Loughran S, Calder N, MacGregor FB, et al. Quality of life and voice following endoscopic resection or radiotherapy for early glottic cancer. Clin Otolaryngol 2005;30 (1):42-7.

[16] Aaltonen LM, Rautiainen N, Sellman J, et al. Voice quality after treatment of early vocal cord cancer: a randomized trial comparing laser surgery with radiation therapy. Int J Radiat Oncol Biol Phys 2014;90 (2):255-60.

[17] Jotic A, Stankovic P, Jesic S, et al. Voice quality after treatment of early glottic carcinoma. J Voice 2012;26 (3):381-9.

[18] Hocevar-Boltezar I, Zargi M, Strojan P. Risk factors for voice quality after radiotherapy for early glottic cancer. Radiother Oncol 2009;93 (3):524-9. 
[19] Karlsson T, Tuomi L, Andrell P, et al. Effects of voice rehabilitation after radiotherapy for laryngeal cancer: a longitudinal study. Logoped Phoniatr Vocol 2017;42 (4):167-77.

[20] Tuomi L, Bjorkner E, Finizia C, et al. Voice outcome in patients treated for laryngeal cancer: efficacy of voice rehabilitation. J Voice 2014;28 (1):62-8.

[21] Al-Mamgani A, Tans L, Van Rooij P, et al. A singleinstitutional experience of 15 years of treating T3 laryngeal cancer with primary radiotherapy, with or without chemotherapy. Int J Radiat Oncol Biol Phys 2012;83 (3):1000-6.

[22] Carrara-De AE, Feher O, Barros APB, et al. Voice and swallowing in patients enrolled in a larynx preservation trial. Arch Otolaryngol Head Neck Surg 2003;129 (7):733-8.
[23] Fung K, Lyden TH, Lee J, et al. Voice and swallowing outcomes of an organ-preservation trial for advanced laryngeal cancer. Int J Radiat Oncol Biol Phys 2005;63 (5):1395-9.

[24] Gillespie AI, Dastolfo C, Magid N, et al. Acoustic analysis of four common voice diagnoses: moving toward disorder-specific assessment. J Voice 2014;28 (5):582-8.

[25] Tuomi L, Karlsson T, Johansson M, et al. Health-related quality of life and voice following radiotherapy for laryngeal cancer-a comparison between glottic and supraglottic tumours. Acta Oncol 2015;54 (1):73-9. 